\title{
Interactive comment on "Time-lapse monitoring of root water uptake using electrical resistivity tomography and Mise-à-la-Masse: a vineyard infiltration experiment” by Benjamin Mary et al.
}

\section{Paul Hallett (Editor) \\ paul.hallett@abdn.ac.uk}

Received and published: 14 June 2019

Three reviewers have now provided very helpful and thorough comments on your manuscript. Reviewers $1 \& 3$ have concerns about the novelty of the study over Mary et al. (2018), which will need to be addressed with a strong and convincing statement about the originality of the submitted paper.

SOIL allows for public comment on all manuscripts so the paper will stay open until 3 July 2019, but you are welcome to comment on the reviews thus far. 